\title{
Quantitative assessment and determinants of the papillary microvasculature in healthy subjects
}

Li-jun Zhou ${ }^{1,2}$, Xiu-zhi Luo ${ }^{2}$, Pei-yang Shen ${ }^{1,2}$, Xin Li ${ }^{2}$, Peng Su${ }^{2}$, Zhe Zhu ${ }^{3}$, Shi-gang Yan ${ }^{2}$, Xiang-bin Kong ${ }^{2 *}$ and Xiao-he Lu $^{1^{*}}$

\begin{abstract}
Background: It is critical to monitor the optic disc's vessel density using Optical coherence tomography angiography (OCTA) and evaluate its determinants. In the current study, we investigate the superficial vessel density (VD) of the papillary microvasculature and its determinants in healthy subjects of Southern China.

Methods: This was a prospective, cross-sectional study. Superficial VD in healthy individuals' optic disc region was measured by OCTA. The factors associated with ocular and systemic parameters were analyzed using a generalized estimation equation (GEE) model.

Results: A total of 510 eyes of 260 healthy subjects were analyzed in the study. The total VD in the optic disc area was $17.21 \pm 2.15 \mathrm{~mm}^{-1}\left(95 \% \mathrm{Cl}, 17.02-17.40 \mathrm{~mm}^{-1}\right)$. The VD in the inner ring and the outer ring of the optic disc were significantly higher compared with the central ring, while the VD of the superior quadrant and inferior quadrant was significantly higher compared with the temporal and nasal quadrant. After adjusting for the ocular factors and systemic factors, $A L(\beta=-0.4917, P=0.0003)$, disc area $(\beta=-0.3748, P=0.0143)$, CMT $(\beta=-0.0183$, $P=0.0003)$ and SSI $(\beta=1.0588, P<0.001)$ were significantly associated with total VD of the optic disc.
\end{abstract}

Conclusion: The mean total VD in the optic disc area was $17.21 \pm 2.15 \mathrm{~mm}^{-1}$ in healthy subjects, and the superior and inferior VD was significantly higher than the temporal and nasal VD. AL, disc area, CMT, and SSI may affect the total VD in the optic disc area and should be considered in clinical practice.

Keywords: Optical coherence tomography angiography, Superficial vessel density, Healthy subjects, Optic disc, Axial length

\footnotetext{
* Correspondence: Xiangbin_kong@sina.com; luxh63@163.com

2Department of Ophthalmology, Affiliated Foshan Hospital, Southern Medical University, Foshan 528000, China

'Department of Ophthalmology, Zhujiang Hospital, Southern Medical University, Guangzhou 515282, China

Full list of author information is available at the end of the article
}

(c) The Author(s). 2021 Open Access This article is licensed under a Creative Commons Attribution 4.0 International License, which permits use, sharing, adaptation, distribution and reproduction in any medium or format, as long as you give appropriate credit to the original author(s) and the source, provide a link to the Creative Commons licence, and indicate if changes were made. The images or other third party material in this article are included in the article's Creative Commons licence, unless indicated otherwise in a credit line to the material. If material is not included in the article's Creative Commons licence and your intended use is not permitted by statutory regulation or exceeds the permitted use, you will need to obtain permission directly from the copyright holder. To view a copy of this licence, visit http://creativecommons.org/licenses/by/4.0/ The Creative Commons Public Domain Dedication waiver (http://creativecommons.org/publicdomain/zero/1.0/) applies to the data made available in this article, unless otherwise stated in a credit line to the data. 


\section{Background}

The optic disc, an important anatomic structure where the retinal nerve fiber converges, is a part of the nerve system. Blood flow plays an essential role in maintaining the normal function of the optic disc. Previous studies have demonstrated abnormal blood flow in optic neuropathies $[1,2]$. Therefore, it is critical to quantify changes in microcirculation as an early marker for some diseases.

Fundus fluorescein angiography (FFA) has been the primary method used to examine the optic disc and retinal capillary circulation for many years [3]. However, FFA is an invasive examination and cannot quantify the vessel density (VD) [4]. Optical coherence tomography angiography (OCTA) is a recent non-invasive technology that can visualize and quantify the retinal and papillary microvasculature $[5,6]$. Studies have demonstrated abnormal blood flow changes of the retina and optic discs in some diseases, including retinal vein occlusion [7], anterior ischemic optic neuropathy $[8,9]$, glaucoma [10], diabetic retinopathy $[11,12]$, and hypertension retinopathy [13].

However, there are scarce normative OCTA data from a healthy population, particularly concerning the optic disc's VD [14, 15]. Additionally, there is little understanding of the determinants associated with papillary VD. Therefore, we performed this study to provide normative papillary VD data in healthy individuals and further investigated factors associated with ocular parameters and systematic parameters.

\section{Methods}

\section{Ethical approval}

Ethics approval was obtained from the Institutional Review Board of Foshan Second Hospital (KJ20190012). This was a cross-sectional study conducted at the Department of Ophthalmology, Foshan Second Hospital, Southern Medical University, between May 2019 and April 2020. This study met the Declaration of Helsinki's tenets and was registered on the Chinese Clinical Trial Registry (identifier: ChiCTR1900024921). Informed consent was obtained from all subjects or, if subjects are under 18 , from a parent or legal guardian before starting the study.

\section{Study population}

Healthy subjects who had a best-corrected visual acuity (BCVA) of 20/25 or better without clinical evidence of ocular diseases were included in the study. The inclusion criteria were as follows: intraocular pressure (IOP) of less than $21 \mathrm{mmHg}$, normal findings of the slit lamp and fundus examination. The exclusion criteria were: a history of ocular surgery or ocular trauma, significant opacity media preventing high-quality imaging, glaucoma, systemic diseases, such as hypertension, diabetes mellitus, retinal and choroidal disease, for example, retinal vein obstruction, macular hole, and choroidal retinopathy.

\section{Ophthalmic examinations}

All subjects underwent complete ophthalmic examinations, including BCVA, slit-lamp examination, spherical equivalent (SE), IOP, fundus evaluation, and OCTA examination. Ocular biometric parameters, including central corneal thickness (CCT), axial length (AL), anterior chamber depth (ACD), and lens thickness (LT), were performed using optical low-coherence reflectometry (LenStar LS 900, Haag-Streit, Inc., Koeniz, Switzerland). The central macular thickness (CMT, central $1 \mathrm{~mm}$ ) was assessed using the macular cube $512 \times 128$ model of the optical coherence tomography (Cirrus 5000 HD-OCT; Carl Zeiss Meditec, Inc., Dublin, CA). Disc area and cup area were measured by a 200 X 200 optic disc cube scan. Arterial blood pressure, body weight, and height were recorded. The ocular perfusion pressure (OPP) was calculated according to the equations: $\mathrm{OPP}=2 / 3$ (mean arterial pressure - IOP), where mean arterial pressure $=$ $1 / 3$ systolic pressure $+2 / 3$ diastolic blood pressure. The body mass index (BMI) was also calculated as a variable to explore its association with the optic disc VD.

OCTA examination was performed for all subjects using the Zeiss Cirrus HD-OCT 5000 and Angioplex device. To obtain the VD of the superficial capillary plexus (SCP) on the optic disc, the scanning model $6 \mathrm{X} 6 \mathrm{~mm}$ was used with a real-time eye-tracking system. The SCP was measured from the internal limiting membrane (ILM) to the inner plexiform layer (IPL). The VD was defined as the total length of perfused vasculature per unit area $\left(\mathrm{mm}^{-1}\right)$. The papillary VD was automatically divided into four sections: the central ring, inner ring, outer ring, and full circle (Fig. 1a) and was calculated automatically by the OCTA software. Each ring was grouped into four quadrants based on the Early Treatment of Diabetic Retinopathy Study. In this study, the total VD referred to the VD in the full circle area (Fig. 1b). The images of OCTA with a quality signal strength of 7 or higher were analyzed.

\section{Statistical analysis}

Data were presented as mean \pm standard deviation (SD) for continuous variables and frequency (\%) for categorical variables. For associated factors of total papillary $\mathrm{VD}$, regression analysis was performed using a generalized estimation equation (GEE) model that was applied to adjust the possible intra-eyes correlation. Firstly, univariate GEE was performed to identify potential prognostic factors. The dependent variables, including systematic parameters and ocular parameters, were selected into the models, respectively. Then, variables 

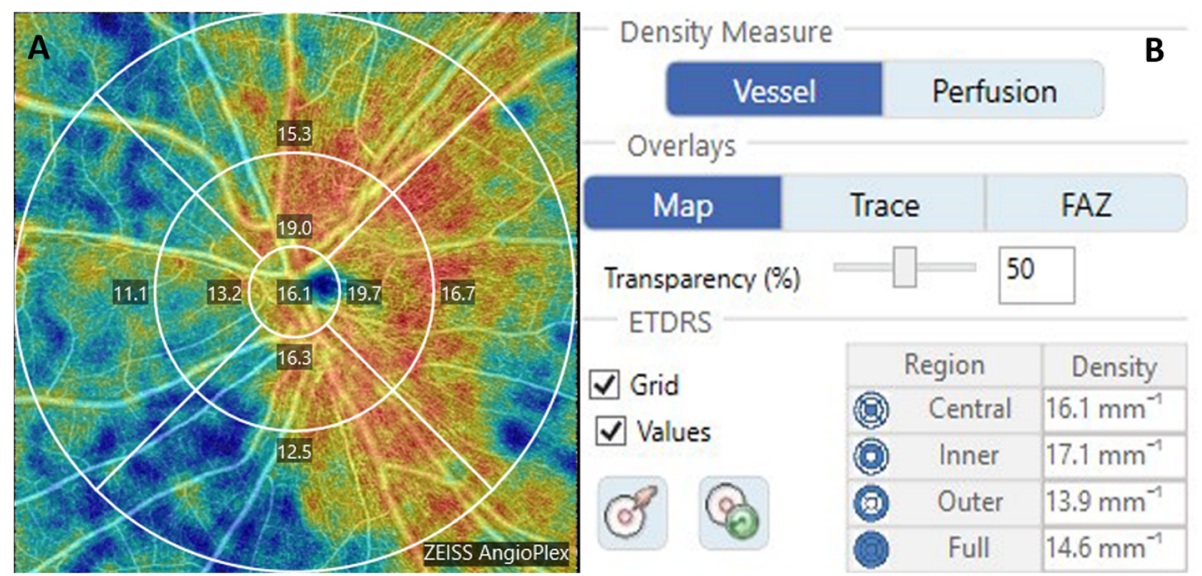

Fig. 1 Vessel density of superficial capillary in the optic disc. a Shows four quadrants' vessel density (superior, temporal, inferior, and nasal) in the inner ring and outer ring. b Shows the vessel density of different rings (central, inner, outer, and full)

with $P<0.30$ in univariate analysis and potential confounders (age and gender) were included in the multivariate GEE model. Regression coefficients with 95\% confidence intervals $(\mathrm{CI})$ were presented. SAS statistical software version 9.4 (SAS Institute Inc., Cary, NC) was used for statistical analyses. A $P$-value $<0.05$ was considered statistically significant.

\section{Results}

Of 315 screened individuals, a total of 263 subjects $(83.49 \%)$ were enrolled in the study. Fifty-two subjects were excluded from analysis, including 8 subjects with hypertension, 4 subjects with diabetics, 8 subjects with high IOP, 25 subjects with remarkable cataract, 4 subjects with an ocular surgery history, 3 subjects with lack of refraction or biometric data. Additionally, of the enrolled 526 eyes of 263 individuals, 16 eyes were excluded because the imaging signal strength index was less than 7, including 3 bilateral individuals and 10 unilateral individuals. Finally, the 510 eyes of 260 individuals remaining subjects were analyzed in this study (Fig. 2).

The subjects' mean age was $38.32 \pm 21.89$ years $(95 \%$ CI, 35.64 - 40.99, range, 5-84 years), and 123 (47.31\%) subjects were male. All demographic data were presented in Table 1.The mean VD was $5.28 \pm 4.30 \mathrm{~mm}^{-1}$ $\left(95 \% \mathrm{CI}, 4.91-5.66 \mathrm{~mm}^{-1}\right)$ in the center ring, $18.15 \pm$ $3.34 \mathrm{~mm}^{-1}\left(95 \% \mathrm{CI}, 17.86-18.44 \mathrm{~mm}^{-1}\right)$ in the inner,

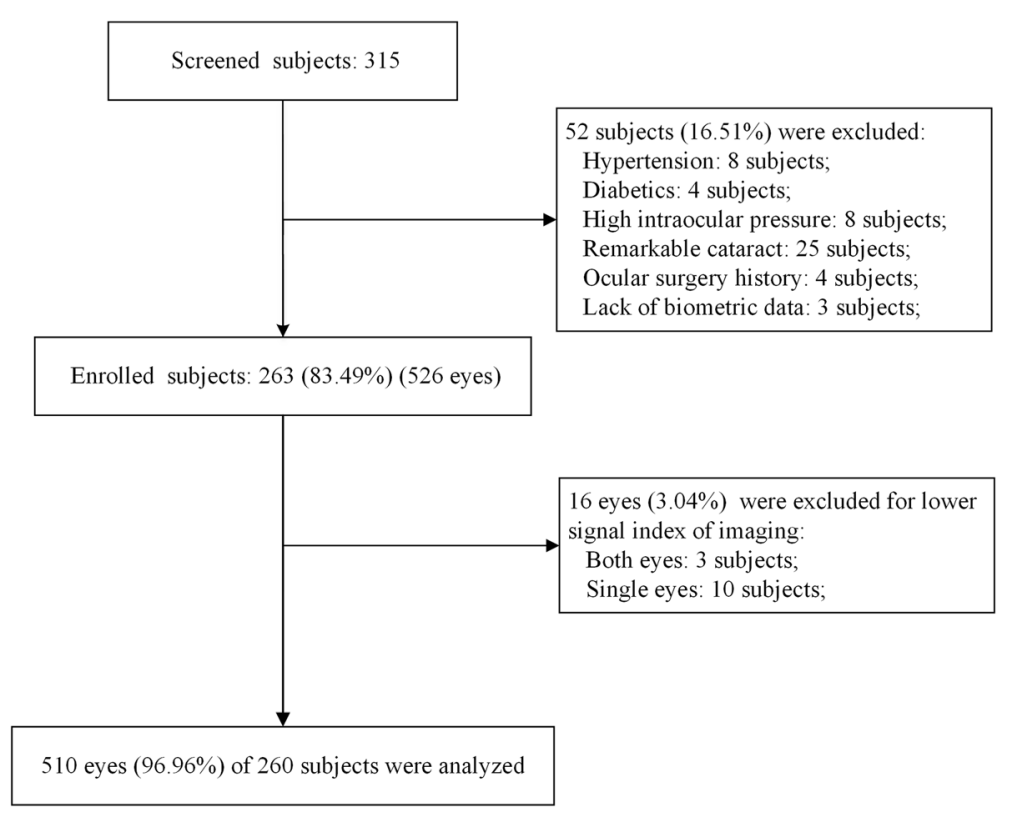

Fig. 2 Flowchart of inclusion and exclusion 
Table 1 Demographic and clinical characteristics of study participants

\begin{tabular}{|c|c|c|}
\hline Variables & Means \pm SD & $95 \% \mathrm{Cl}$ \\
\hline Age (years) & $38.32 \pm 21.89$ & $35.64-40.99$ \\
\hline Body weight (kg) & $52.59 \pm 14.13$ & $50.87-54.32$ \\
\hline Body height (cm) & $158.25 \pm 11.62$ & 156.83-159.67 \\
\hline $\mathrm{BMI}\left(\mathrm{kg} / \mathrm{m}^{2}\right)$ & $20.64 \pm 3.89$ & $20.16-21.11$ \\
\hline Systolic (mmHg) & $114.36 \pm 16.01$ & $112.40-116.31$ \\
\hline Diastolic (mmHg) & $72.39 \pm 10.12$ & $71.16-73.63$ \\
\hline $\mathrm{OPP}(\mathrm{mmHg})$ & $42.87 \pm 8.09$ & $41.88-43.86$ \\
\hline SE (diopter) & $-1.62 \pm 2.52$ & $-1.84--1.40$ \\
\hline IOP (mmHg) & $14.82 \pm 2.72$ & $14.59-15.06$ \\
\hline $\mathrm{CCT}(\mu \mathrm{m})$ & $537.86 \pm 31.83$ & $535.09-540.63$ \\
\hline $\mathrm{ACD}(\mathrm{mm})$ & $3.40 \pm 0.43$ & $3.36-3.44$ \\
\hline $\mathrm{LT}(\mathrm{mm})$ & $4.01 \pm 0.57$ & $3.96-4.06$ \\
\hline $\mathrm{AL}(\mathrm{mm})$ & $24.10 \pm 1.21$ & $24.00-24.21$ \\
\hline CMT $(\mu \mathrm{m})$ & $279.99 \pm 13.91$ & $278.78-281.20$ \\
\hline SSI & $9.95 \pm 1.10$ & $8.86-9.05$ \\
\hline Disc area $\left(\mathrm{mm}^{2}\right)$ & $1.91 \pm 0.46$ & $1.87-1.95$ \\
\hline Cup area $\left(\mathrm{mm}^{2}\right)$ & $0.50 \pm 0.40$ & $0.46-0.53$ \\
\hline
\end{tabular}

$B M I$ body max index, OPP ocular perfusion pressure, $S E$ spherical equivalent, $I O P$ intraocular pressure, $C C T$ central corneal thickness, $A C D$ anterior chamber depth, $L T$ lens thickness, $A L$ axial length, $C M T$ central macular thickness, SSI signal strength index

and $17.53 \pm 2.93 \mathrm{~mm}^{-1}$ (95\% CI, $7.27-17.78 \mathrm{~mm}^{-1}$ ) in the outer, respectively. The VD of the inner and outer was significantly higher compared with the center $(P<$ 0.001 ), but no significant difference was found between the inner ring and outer ring $(P=0.8992)$. In the outer ring (Fig. 3a) and the inner ring (Fig. 3b) of the optic disc OCTA, the VD in the superior quadrant and inferior quadrant was statistically higher than the temporal and nasal quadrant.

The mean superficial VD in the optic disc's full circle was $\quad 17.20 \pm 2.15 \mathrm{~mm}^{-1}\left(95 \% \quad \mathrm{CI}, \quad 17.02-17.40 \mathrm{~mm}^{-1}\right.$; range, $\left.5.30-19.70 \mathrm{~mm}^{-1}\right)$. Univariate regression analysis showed that the $\operatorname{SE}(\beta=0.2018, P<0.001)$, the $\operatorname{AL}(\beta=$
- 0.5477, $P<0.001)$, the CMT $(\beta=0.0232, P=0.0006)$, and the SSI $(\beta=1.0832, P<0.001)$ were associated factors, which was significantly affected the papillary VD of SCP in healthy individuals. Besides, the papillary VD was not significantly associated with age $(P=0.7771)$, gender (male vs. female, $P=-0.2956)$, body weight $(P=0.6156)$, body height $(P=0.0554)$, BMI $(P=0.6145)$, systolic pressure $(P=0.5152)$, diastolic pressure $(P=0.5182)$, IOP $(P=0.2579)$, CCT $(P=0.8471)$, ACD $(P=0.1074)$, LT $(P=0.2778)$, disc area $(P=0.2510)$ and cup area $(P=$ 0.9771) (Table 2).Variables with $\mathrm{P}<0.30$ in univariable analysis and potential confounders (age, gender) were included in multivariate analysis models. AL $(\beta=-0.4917$, $P=0.0003)$ and disc area $(\beta=-0.3748, P=0.0143)$ were significantly negatively associated with total VD of the optic disc, while CMT $(\beta=-0.0183, P=0.0003)$ and SSI $(\beta=1.0588, P<0.001)$ were positively related to total VD of the optic disc (Table 3). However, after controlling the ocular parameters and systemic factors, age, gender, body height, SE, ACD, and LT were not significantly associated with the optic disc's total VD (Table 3).

\section{Discussion}

Normative data of papillary VD is needed and has important implications in understanding the development of optic neuropathies, for example, optic neuritis, anterior ischemic optic neuropathy, glaucoma, and other diseases [9, 16-18]. This study investigated the papillary VD of SCP and its determinants in healthy individuals aged 5 to 84 . The results showed that the mean total VD of the papillary area was $17.21 \pm 2.15 \mathrm{~mm}^{-1}(95 \% \mathrm{CI}$, $\left.17.02-17.40 \mathrm{~mm}^{-1}\right)$. AL, CMT, SSI, and disc area significantly affected the total VD after adjusting for the confounders. Additionally, the center ring's VD was considerably lower than that in the inner and outer regions. The VD of the superior sector and inferior sectors was higher compared with the temporal and nasal sector.

There were different VD data of superficial capillary (SCP) in the optic disc from healthy individuals using other OCTA devices. Fernandez-Vigo et al. measured
A

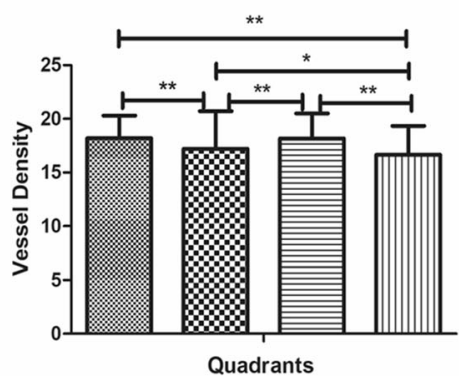

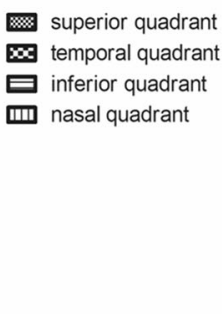

B Quadrants VD in inner ring

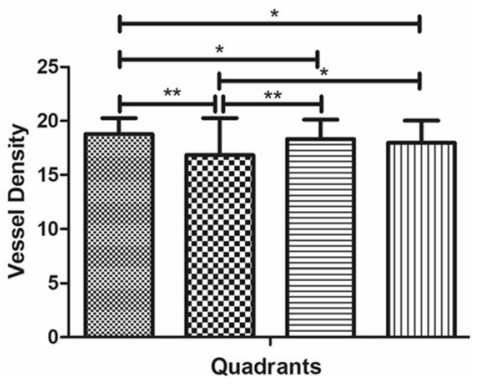

Fig. 3 Comparison of vessel density of different quadrants in the outer (a) and the inner ring (b) 
Table 2 Univariate analysis of the associated factors of total vessel VD in the optic disc

\begin{tabular}{|c|c|c|}
\hline Variables & $\beta(95 \% \mathrm{Cl})$ & $P$-value \\
\hline Age (year) & $0.0005(-0.0008-0.0117)$ & 0.7771 \\
\hline Gender (male vs. female) & $-0.2358(-0.6777-0.2061)$ & 0.2956 \\
\hline Body weight (kg) & $-0.0041(-0.0200-0.0119)$ & 0.6156 \\
\hline Body height $(\mathrm{cm})$ & $-0.0193(-0.0390-0.0004)$ & 0.0554 \\
\hline $\mathrm{BMI}\left(\mathrm{kg} / \mathrm{m}^{2}\right)$ & $0.0145(-0.0420-0.0711)$ & 0.6145 \\
\hline Systolic pressure $(\mathrm{mmHg})$ & $-0.0045(-0.0181-0.0091)$ & 0.5152 \\
\hline Diastolic pressure $(\mathrm{mmHg})$ & $0.0069(-0.0141-0.0279)$ & 0.5181 \\
\hline OPP (mmHg) & $0.0066(-0.0185-0.0318)$ & 0.6045 \\
\hline SE (diopter) & $0.2018(0.1015-0.3021)$ & $<0.001$ \\
\hline IOP (mmHg) & $-0.0462(-0.1261-0.0338)$ & 0.2579 \\
\hline $\mathrm{CCT}(\mu \mathrm{m})$ & $-0.0007(-0.0074-0.0061)$ & 0.8471 \\
\hline $\mathrm{ACD}(\mathrm{mm})$ & $-0.3663(-0.8121-0.0796)$ & 0.1074 \\
\hline $\mathrm{LT}(\mathrm{mm})$ & $0.2024(-0.1631-0.5680)$ & 0.2778 \\
\hline $\mathrm{AL}(\mathrm{mm})$ & $-0.5477(-0.7533--0.3422)$ & $<0.001$ \\
\hline CMT $(\mu \mathrm{m})$ & $0.0232(0.0100-0.0365)$ & 0.0006 \\
\hline SSI & $1.0832(0.9082-1.2582)$ & $<0.001$ \\
\hline Disc area $\left(\mathrm{mm}^{2}\right)$ & $0.2475(-0.1751-0.6702)$ & 0.2510 \\
\hline Cup area $\left(\mathrm{mm}^{2}\right)$ & $0.0076(-0.5128-0.5281)$ & 0.9771 \\
\hline
\end{tabular}

$\mathrm{Cl}$ confidence intervals, $B M I$ body max index, OPP ocular perfusion pressure, $S E$ spherical equivalent, IOP intraocular pressure, $C C T$ central corneal thickness, $A C D$ anterior chamber depth, $L T$ lens thickness, $A L$ axial length, $C M T$ central Macular thickness, SSI signal strength index

the optic nerve head VD using swept-source optical coherence tomography angiography. They reported that the VD for central SCP was $45.3 \%$. The VD in vertical quadrants (60.5 and $61.9 \%$ in superior and inferior, respectively) was higher than the horizontal quadrants (53.4 and 52.4\% in temporal and nasal, respectively) [19]. However, Zhang et al. found no difference between

Table 3 Multivariate analysis of the associated factors of total vessel VD in the optic disc

\begin{tabular}{lll}
\hline Variable & $\boldsymbol{\beta} \mathbf{( 9 5 \% ~ C l )}$ & $\boldsymbol{P}$-value \\
\hline Age (year) & $0.0057(-0.0130-0.0243)$ & 0.5523 \\
Gender (male vs. female) & $-0.2265(-0.6005-0.1475)$ & 0.2353 \\
Body height (cm) & $-0.0158(-0.0323-0.0006)$ & 0.0588 \\
SE (diopter) & $-0.0096(-0.0096-0.1089)$ & 0.8743 \\
IOP (mmHg) & $-0.0224(-0.0866-0.0417)$ & 0.4929 \\
ACD $(\mathrm{mm})$ & $0.4096(-0.1858-1.0050)$ & 0.1775 \\
LT $(\mathrm{mm})$ & $-0.3154(-0.9939-0.3630)$ & 0.3622 \\
AL $(\mathrm{mm})$ & $-0.4917(-0.7552--0.2281)$ & 0.0003 \\
CMT $(\mu \mathrm{m})$ & $0.0183(0.0083-0.0282)$ & 0.0003 \\
SSI & $1.0588(0.8983-1.2193)$ & $<0.001$ \\
Disc area $\left(\mathrm{mm}^{2}\right)$ & $-0.3748(-0.6745--0.0750)$ & 0.0143 \\
\hline
\end{tabular}

$\mathrm{Cl}$ confidence intervals, SE spherical equivalent, IOP intraocular pressure, $A C D$ anterior chamber depth, $L T$ lens thickness, $A L$ axial length, $C M T$ central Macular thickness, SSI signal strength index superior and inferior peripapillary areas in 71 healthy subjects aged 5 to 18 [20]. Bazvand et al. used the RTVue XR Avanti (Optovue, Fremont, CA, USA) to measure the peripapillary VD in 79 healthy eyes of individuals with a mean age $37.03 \pm 11.27$ years (12 to 67 years). They found that the total VD of the optic disc was $56.03 \% \pm 4.55 \%$ [17]. A study with a large sample size of 346 eyes also revealed that the peripapillary VD was $57.2 \pm 5.7 \%$ for SCP, measured by the swept-source optical coherence tomography angiography (SS-OCTA). Further analysis showed that vertical peripapillary VD was significantly higher compared with the horizontal measurements [15]. In our study, a similar finding was observed that VD in the superior quadrant and inferior quadrant was significantly higher than the temporal and nasal quadrants. Why did the VD vary from studies? A possible explanation was that there could have been a lack of standardization of data due to different OCTA devices in those studies. Besides, there was a difference in the range and depth of the optic disc scanned by OCTA. Enrolled subjects also differed in each study. Additionally, each individual varies in the disc-fovea axis, impacting the asymmetry of retinal fiber layer (RNFL) thickness [21]. Greater RNFL thickness should require more blood flow to meet the need for tissue metabolism. As a result, the vessel density is positively related to the RNFL thickness [22].

Different determinants affecting papillary VD have been reported in recent studies. The impact of age and gender on the VD of the optic disc remains controversial. Several studies demonstrated a significant impact of age and gender on the VD, while others reported no influence. Wang et al. and Jo et al. observed that the VD decreased with age $[23,24]$. Similarly, Zhang et al. also reported that age could account for $15 \%$ of VD variations [20]. However, Rao et al. found that age did not influence the papillary VD [14]. Chang et al. found that male sex was associated with reduced VD [25]. In contrast, Mansoori et al. found no association between sex and papillary VD in 52 healthy subjects using RTVue XR 100 Avanti OCT [26]. Another study also showed no association between sex and VD of the papillary area [15]. Consistent with those results, age and sex were not significantly associated with the optic disc's superficial VD in the present study. One possible explanation for these different results is that those studies varied from inclusion criteria of subjects, especially in age. Besides, various machines and scan models also could account for the discrepancy to some extent.

Several authors have investigated the association between ocular parameters and VD. Nelson et al. found that AL was negatively associated with peripapillary VD in 1029 eyes from 1029 subjects [27]. Other studies also demonstrated similar results $[28,29]$. A decrease in total 
papillary VD with AL $(\beta=-0.4917, P=0.0003)$ was found in this study after controlling other variables. A significantly positive association between the mean macular thickness and total papillary VD was found in this study. A possible explanation may be that a thicker retina has a higher demand for nutrients and oxygen [30]. Besides, the multivariate analysis demonstrated that disc area was negatively associated with total VD, which is consistent with previous findings [31].

Systemic factors, such as blood pressure, are expected to affect VD [14, 32]. Interestingly, blood pressure, including diastolic pressure, systolic pressure, and OPP, was not significantly associated with papillary VD in healthy subjects in the present study. Similar findings are demonstrated by Rao et al. and Liu et al. [16, 25]. We speculate that it may be related to the autoregulation of blood pressure. Given the healthy individuals in our study, blood pressure and OPP changes did not significantly affect the ocular blood.

It is worth noting that SSI is significantly associated with the VD in optic disc both in the univariate model and multivariate. To ensure imaging quality and reduce the impact of SSI on VD, we only enrolled the eyes with SSI greater than 7. Even so, SSI still has a more substantial effect on the VD. The result was consistent with previous studies [33, 34]. Therefore, the SSI should be taken into consideration when measuring the VD by OCTA.

This study also has limitations. Firstly, we have not performed a correction of our data for potential magnification in the image sizes. Axial length may lead to changes in image size magnification, especially in myopia. The true size of the fundus area imaged is related to the magnification of the camera and eye [35]. Axial length variation also has an impact on the superficial VD [36]. There are some individuals with myopia in our study. In the follow-up work, we need to investigate its effects on VD further. Secondly, the disc's large retinal vessel is not removed automatically in our study, which can generate projection artifacts on the deeper layer and impact on the VD. However, we focus on the superficial VD in healthy individuals. So it maybe has little effect on superficial VD in our study [37, 38]. Additionally, subjects younger than 5 years are not included in the present study because they are likely not to finish the OCTA examination for high-quality imaging. Finally, although the study presents a normative database from Southern China, it may not represent the entire population.

In conclusion, using a relatively large sample size (510 eyes), the superficial VD measurement of the optic disc is measured using OCTA. The correlation from both eyes of a person is adjusted with the GEE regression model. We found that the mean of the total VD in the optic disc area was $17.21 \pm 2.15 \mathrm{~mm}^{-1}$ (95\% CI, 17.02 $\left.17.40 \mathrm{~mm}^{-1}\right)$. The univariate analysis shows that the body height, the SE, the $\mathrm{AL}$, and the CMT are associated with total VD. However, after adjusting for other variables, the multivariate regression model showed that the AL, CMT, SSI, and disc area are significantly related to total papillary VD. Therefore, when evaluating the optic disc's superficial VD in clinical practice, these parameters should be taken into account.

\section{Abbreviations \\ ACD: Anterior chamber depth; AL: Axial length; BCVA: Best-corrected visual acuity; BMI: Body mass index; CCT: Central corneal thickness; Cl: Confidence intervals; CMT: Central macular thickness; FFA: Fundus fluorescein angiography; GEE: Generalized estimation equation; IOP: Intraocular pressure; OCTA: Optical coherence tomography angiography; OPP: Ocular perfusion pressure; SCP: Superficial capillary plexus; SD: Standard deviation; \\ SE: Spherical equivalent; SSI: Signal strength index; VD: Vessel density}

\section{Authors' contributions}

ZLJ: Methodology, Data curation, Writing-Original draft; LXZ: Formal analysis; SPY: Visualization; LX: Supervision; SP: Supervision; ZZ: Writing-Review \& Editing; YSG: Project administration; KXB: Conceptualization, Methodology; LXH: Conceptualization, Writing - Review \& Editing. All authors reviewed the manuscript. The author(s) read and approved the final manuscript.

\section{Funding}

Supported by Guangdong Basic and Applied Basic Research Foundation (2019B1515120011); Science and Technology Planning Project of Foshan City (1920001000811).

\section{Availability of data and materials}

The datasets used in the current study are available from the corresponding author on a reasonable request.

\section{Declarations}

Ethics approval and consent to participate

The study protocol was approved by the Institutional Review Board of Foshan Second Hospital (KJ20190012), and all subjects provided the written informed consent.. The study was conducted following the tenets of the Declaration of Helsinki.

\section{Consent for publication}

Not applicable.

Competing interests

The authors declare that they have no competing interests.

\section{Author details}

${ }^{1}$ Department of Ophthalmology, Zhujiang Hospital, Southern Medical University, Guangzhou 515282, China. 'Department of Ophthalmology, Affiliated Foshan Hospital, Southern Medical University, Foshan 528000, China. ${ }^{3}$ Department of Medicine, Division of Regenerative Medicine, University of California, San Diego, School of Medicine, La Jolla, CA 92037, USA.

Received: 29 October 2020 Accepted: 5 March 2021

Published online: 20 March 2021

\section{References}

1. Akil H, Falavarjani KG, Sadda SR, Sadun AA. Optical coherence tomography angiography of the optic disc; an overview. J Ophthalmic Vis Res. 2017; 12(1):98-105. https://doi.org/10.4103/2008-322X.200162.

2. Wylegala A. Principles of OCTA and applications in clinical neurology. Curr Neurol Neurosci Rep. 2018;18(12):96. https://doi.org/10.1007/s11910018-0911-x. 
3. Marmor MF, Ravin JG. Fluorescein angiography: insight and serendipity a half century ago. Arch Ophthalmol. 2011;129(7):943-8. https://doi.org/10.1 001/archophthalmol.2011.160.

4. Keane PA, Sadda SR. Retinal imaging in the twenty-first century: state of the art and future directions. Ophthalmology. 2014;121(12):2489-500. https:// doi.org/10.1016/j.ophtha.2014.07.054.

5. Brucher VC, Storp JJ, Eter N, Alnawaiseh M. Optical coherence tomography angiography-derived flow density: a review of the influencing factors. Graefes Arch Clin Exp Ophthalmol. 2020;258(4):701-10. https://doi.org/10.1 007/s00417-019-04553-2.

6. Schwartz DM, Fingler J, Kim DY, Zawadzki RJ, Morse LS, Park SS, Fraser SE, Werner JS. Phase-variance optical coherence tomography: a technique for noninvasive angiography. Ophthalmology. 2014;121(1):180-7. https://doi. org/10.1016/j.ophtha.2013.09.002.

7. Chung CY, Tang HHY, Li SH, Li KKW. Differential microvascular assessment of retinal vein occlusion with coherence tomography angiography and fluorescein angiography: a blinded comparative study. Int Ophthalmol. 2018;38(3):1119-28. https://doi.org/10.1007/s10792-017-0570-y.

8. Kim MK, Kim US. Analysis of fundus photography and fluorescein angiography in nonarteritic anterior ischemic optic neuropathy and optic neuritis. Korean J Ophthalmol. 2016:30(4):289-94. https://doi.org/10.3341/ kjo.2016.30.4.289.

9. Oto S, Yilmaz G, Cakmakci S, Aydin P. Indocyanine green and fluorescein angiography in nonarteritic anterior ischemic optic neuropathy. Retina. 2002;22(2):187-91. https://doi.org/10.1097/00006982-200204000-00009.

10. Kim JA, Kim TW, Lee EJ, Girard MJA, Mari JM. Microvascular changes in peripapillary and optic nerve head tissues after trabeculectomy in primary open-angle glaucoma. Invest Ophthalmol Vis Sci. 2018;59(11):4614-21. https://doi.org/10.1167/iovs.18-25038.

11. Shin Y-I, Nam KY, Lee SE, Lee M-W, Lim H-B, Jo Y-J, Kim J-Y. Peripapillary microvasculature in patients with diabetes mellitus: an optical coherence tomography angiography study. Sci Rep. 2019;9(1):15814. https://doi.org/1 0.1038/s41598-019-52354-8.

12. Vujosevic S, Muraca A, Gatti V, Masoero L, Brambilla M, Cannillo B, Villani E, Nucci P, De Cilla S. Peripapillary microvascular and neural changes in diabetes mellitus: an OCT-angiography study. Invest Ophthalmol Vis Sci. 2018;59(12):5074-81. https://doi.org/10.1167/iovs.18-24891.

13. Shin Yl, Nam KY, Lee WH, Ryu CK, Lim HB, Jo YJ, Kim JY. Peripapillary microvascular changes in patients with systemic hypertension: An optical coherence tomography angiography study. Sci Rep. 2020;10(1):6541. https:// doi.org/10.1038/s41598-020-63603-6.

14. Rao HL, Pradhan ZS, Weinreb RN, Reddy HB, Riyazuddin M, Sachdeva S, Puttaiah NK, Jayadev C, Webers CAB. Determinants of peripapillary and macular vessel densities measured by optical coherence tomography angiography in normal eyes. J Glaucoma. 2017;26(5):491-7. https://doi.org/1 0.1097/IJG.0000000000000655.

15. Fernandez-Vigo Jl, Kudsieh B, Shi H, De-Pablo-Gomez-de-Liano L, SerranoGarcia I, Ruiz-Moreno JM, Martinez-de-la-Casa JM, Garcia-Feijoo J, Fernandez-Vigo JA. Normative database of peripapillary vessel density measured by optical coherence tomography angiography and correlation study. Curr Eye Res. 2020:1-8.

16. Liu L, Jia Y, Takusagawa HL, Pechauer AD, Edmunds B, Lombardi L, Davis E, Morrison JC, Huang D. Optical coherence tomography angiography of the peripapillary retina in glaucoma. JAMA Ophthalmol. 2015;133(9):1045-52. https://doi.org/10.1001/jamaophthalmol.2015.2225.

17. Bazvand F, Mirshahi R, Fadakar K, Faghihi H, Sabour S, Ghassemi F. The quantitative measurements of vascular density and flow area of optic nerve head using optical coherence tomography angiography. J Glaucoma. 2017; 26(8):735-41. https://doi.org/10.1097/IJG.0000000000000722.

18. Wang L, Murphy O, Caldito NG, Calabresi PA, Saidha S. Emerging applications of Optical Coherence Tomography Angiography (OCTA) in neurological research. Eye Vis (Lond). 2018;5(1):11. https://doi.org/10.1186/s4 0662-018-0104-3.

19. Fernandez-Vigo Jl, Kudsieh B, Macarro-Merino A, Arriola-Villalobos P, Martinez-de-la-Casa JM, Garcia-Feijoo J, Fernandez-Vigo JA. Reproducibility of macular and optic nerve head vessel density measurements by sweptsource optical coherence tomography angiography. Eur J Ophthalmol. 2020;30(4):756-63. https://doi.org/10.1177/1120672119834472.

20. Zhang Y, Zhang B, Fan M, Gao X, Wen X, Li Z, Zeng P, Tan W, Lan Y. The vascular densities of the macula and optic disc in normal eyes from children by optical coherence tomography angiography. Graefes
Arch Clin Exp Ophthalmol. 2020;258(2):437-44. https://doi.org/10.1007/ s00417-019-04466-0.

21. Choi JA, Kim J-S, Park H-YL, Park H, Park CK. The foveal position relative to the optic disc and the retinal nerve fiber layer thickness profile in myopia. Invest Ophthalmol Vis Sci. 2014;55(3):1419-26. https://doi.org/10.1167/ iovs.13-13604.

22. She X, Guo J, Liu X, Zhu H, Li T, Zhou M, Wang F, Sun X. Reliability of vessel density measurements in the peripapillary retina and correlation with retinal nerve fiber layer thickness in healthy subjects using optical coherence tomography angiography. Ophthalmologica. 2018;240(4):183-90. https://doi. org/10.1159/000485957.

23. Jo YH, Sung KR, Shin JW. Effects of age on peripapillary and macular vessel density determined using optical coherence tomography angiography in healthy eyes. Invest Ophthalmol Vis Sci. 2019;60(10):3492-8. https://doi.org/1 0.1167/iovs.19-26848.

24. Wang Q, Chan S, Yang JY, You B, Wang YX, Jonas JB, Wei WB. Vascular density in retina and choriocapillaris as measured by optical coherence tomography angiography. Am J Ophthalmol. 2016;168:95-109. https://doi. org/10.1016/j.ajo.2016.05.005.

25. Chang R, Nelson AJ, LeTran V, Vu B, Burkemper B, Chu Z, Fard A, Kashani $A H$, Xu BY, Wang RK, Varma R, Richter GM, Varma R, McKean-Cowdin R, Torres M, Fairbrother-Crisp A, Choudhury F, Jiang X, Burkemper B, Adamashvili T, Lastra C, Corona E, Wang YP, Douglass J, Barrera J, Linton J. Systemic determinants of peripapillary vessel density in healthy African Americans: the African American eye disease study. Am J Ophthalmol. 2019; 207:240-7. https://doi.org/10.1016/j.ajo.2019.06.014.

26. Mansoori T, Sivaswamy J, Gamalapati JS, Agraharam SG, Balakrishna N. Measurement of radial peripapillary capillary density in the normal human retina using optical coherence tomography angiography. J Glaucoma. 2017; 26(3):241-6. https://doi.org/10.1097/JJG.0000000000000594.

27. Nelson AJ, Chang R, LeTran V, Vu B, Burkemper B, Chu Z, Fard A, Kashani A, Xu B, Wang R, Varma R, Richter GM, for the African American Eye Disease Study Group. Ocular determinants of peripapillary vessel density in healthy African Americans: the African American eye disease study. Invest Ophthalmol Vis Sci. 2019;60(10):3368-73. https:// doi.org/10.1167/iovs.19-27035.

28. Li Y, Miara H, Ouyang P, Jiang B. The comparison of regional RNFL and fundus vasculature by OCTA in Chinese myopia population. J Ophthalmol. 2018;2018:3490962.

29. Wang $X$, Kong $X$, Jiang $C$, Li M, Yu J, Sun $X$. Is the peripapillary retinal perfusion related to myopia in healthy eyes? A prospective comparative study. BMJ Open. 2016;6(3):e010791. https://doi.org/10.1136/bmjopen-2015010791

30. Cheung CY, Li J, Yuan N, Lau GYL, Chan AYF, Lam A, Tang FY, Tham CC, Pang CP, Chen $L$, et al. Quantitative retinal microvasculature in children using swept-source optical coherence tomography: the Hong Kong children eye study. Br J Ophthalmol. 2018.

31. Yun Yl, Kim YW, Lim HB, Lee DH, Kim JH, Oh BL, Jeoung JW, Park KH. Peripapillary vessel parameters and mean ocular perfusion pressure in young healthy eyes: OCT angiography study. Br J Ophthalmol. 2020. https:// doi.org/10.1136/bjophthalmol-2020-316222.

32. Pascual-Prieto J, Burgos-Blasco B, Avila Sanchez-Torija M, Fernandez-Vigo Jl, Arriola-Villalobos P, Barbero Pedraz MA, Garcia-Feijoo J, Martinez-de-la-Casa JM. Utility of optical coherence tomography angiography in detecting vascular retinal damage caused by arterial hypertension. Eur J Ophthalmol. 2020;30(3):579-85. https://doi.org/10.1177/1120672119831159.

33. Lim HB, Kim YW, Kim JM, Jo YJ, Kim JY. The importance of signal strength in quantitative assessment of retinal vessel density using optical coherence tomography angiography. Sci Rep. 2018;8(1):12897. https://doi.org/10.1038/ s41598-018-31321-9.

34. You QS, Chan JCH, Ng ALK, Choy BKN, Shih KC, Cheung JJC, Wong JKW, Shum JWH, Ni MY, Lai JSM, Leung GM, Cheung CMG, Wong TY, Wong IYH. Macular vessel density measured with optical coherence tomography angiography and its associations in a large population-based study. Invest Ophthalmol Vis Sci. 2019;60(14):4830-7. https://doi.org/10.1167/iovs.19-28137.

35. Garway-Heath DF, Rudnicka AR, Lowe T, Foster PJ, Fitzke FW, Hitchings RA. Measurement of optic disc size: equivalence of methods to correct for ocular magnification. Br J Ophthalmol. 1998;82(6):643-9. https://doi.org/1 0.1136/bjo.82.6.643.

36. Sampson DM, Gong P, An D, Menghini M, Hansen A, Mackey DA, Sampson $D D$, Chen FK. Axial length variation impacts on superficial retinal vessel 
density and foveal avascular zone area measurements using optical coherence tomography angiography. Invest Ophthalmol Vis Sci. 2017;58(7): 3065-72. https://doi.org/10.1167/iovs.17-21551.

37. Say EAT, Ferenczy S, Magrath GN, Samara WA, Khoo CTL, Shields CL. Image quality and artifacts on optical coherence tomography angiography: comparison of pathologic and paired fellow eyes in 65 patients with unilateral choroidal melanoma treated with plaque radiotherapy. Retina (Philadelphia, Pa). 2017;37(9):1660-73.

38. Enders C, Lang GE, Dreyhaupt J, Loidl M, Lang GK, Werner JU. Quantity and quality of image artifacts in optical coherence tomography angiography. PLoS One. 2019;14(1):e0210505. https://doi.org/10.1371/ journal.pone.0210505.

\section{Publisher's Note}

Springer Nature remains neutral with regard to jurisdictional claims in published maps and institutional affiliations.

Ready to submit your research? Choose BMC and benefit from:

- fast, convenient online submission

- thorough peer review by experienced researchers in your field

- rapid publication on acceptance

- support for research data, including large and complex data types

- gold Open Access which fosters wider collaboration and increased citations

- maximum visibility for your research: over $100 \mathrm{M}$ website views per year

At $\mathrm{BMC}$, research is always in progress.

Learn more biomedcentral.com/submissions 